
\title{
ACTION OF RADIUM ON DISTILLED WATER.*
}

\author{
THE POTENT CHEMICAL EFFECT OF A NEWLY DISCOVERED GAS.
}

\author{
B Y S I R W I L L I A M R A M S A Y, H.C.B., F.R.S.
}

THE emanation from radium is one of the most potent, if not the most potent chemical agent which xists in nature of all known substances it is endowed with the greatest content of potential energy: for one cubic centimeter contains, and can evolve, nearly three million times as much heat as an equal volume of a mixture of two volumes of hydrogen with one of oxygen. The spontaneous change which it undergoes, moreover, is accompanied by the emission of an immense number of corpuscles, expelled with a velocity approaching that of light in magnitude, and which have a remarkable influence on matter. For some years I have been engaged in studying its chemical action, and in this memoir I shall attempt to describe its action on pure water.

Since the discovery of this gas by Dorn in 1900, it has been the subject of many researches, physical. for the most part. What we know of its properties can be told in a few words.

It is a gas of unknown, but probably considerable density (Rutherford and Miss Brooks, Trans. Roy. Soc. Canada, 1901), which unceasingly escapes from salts of radium, preferably dissolved in water. Its most remarkable property is its spontaneous change into helium (Ramsay and Soddy, Proc. Roy. Soc., 1903, 72, 204 , and $1904,73,346$ ) and other products (radium A, B, C, etc.); the latter also possess a limited life; it is supposed that radium $F$ is identical with polonium. The emanation obeys Boyle's law; its spectrum was examined by Ramsay and Collie (ibid., 1904, 73, 470). Attempts have been made to determine its density by measuring its rate of diffusion, and so to gain knowledge of its molecular weight; the results of such experiments are somewhat unsatisfactory, but appear to indicate a density of about 100 , and a consequent molecular weight of about 200. It resists like argon and its congeners, it is unaffected by sparking with oxygen in presence of caustic potash or by prolonged contact with a red-hot mixture of magnesium dust and lime; it would therefore appear to belong to the helium group of elements. If this be so, its atomic weight and its molecular weight should be identical, for its molecule is probably monatomic. Perhaps its atomic weight is approximately 216.5 , for the mean difference between five pairs of elements, of which one example is tin and lead, is 88.5 ; and this number, added to the atomic weight of xenon, 128, gives 216.5. The number of 216.5 would correspond approximately to a density of 100 .

It can be condensed by cooling it to $-185 \mathrm{deg}$. by means of liquid air (Rutherford and Soddy, Phil. Mag., 1903, [vi], 5, 561). Rutherford and Soddy state that it is non-volatile at temperatures a few degrees below 150 deg.; but it must certainly possess a vapor pressure even at -185 deg., for when a complete vacuum is made over the frozen emanation, in pumping off other gases, luminous bubbles travel down the fall-tube of the Töpler pump.

It emits only a-rays; and its rate of half-decay is 3.71 days (Rutherford), 3.99 (Curie), and 3.86 (Sackur). The Curies discovered that radium continually evolves heat; and Rutherford has shown that the major part of the heat is due to the disintegration of the emanation; the emanation given off by a gramme of radium in an hour evolves about 75 calories. This heat owes its origin, not only to the disintegration of the emanation, but also to the spontaneous change of several of its products. The total heat evolved during the life of a cubic centimeter of emanation is close on 7 million gramme-calories. Now, the heat evolved on explosion of a cubic centimeter of a mixture of hydrogen and oxygen in theoretical quantity is about 3 calories; it follows that during its disintegration the emanation emits nearly $2 \frac{1}{2}$ million times as much heat as that of an equal volume of hydrogen and oxygen combining with explosion to form water.

It was with the design of applying this enormous store of energy that the experiments about to be chronicled were begun, about two years ago. The quantity of radium at my disposal has varied from time to time, for it was in use for other experiments. 1. The Evolution of Heat by the Radium Emanation.-Although Rutherford has made a quantitative estimation of the amount of heat evolved from the emanation, a qualitative confirmation will here be given; any confirmatory evidence has some value.

Two thermometers were constructed; one, an ordinary thermometer, the scale of which registered tenths of degrees; the bulb of the other was hollow, so that quantity of the emanation, mixed with hydrogen, could be introduced into a chamber surrounded by the mercury of the thermometer. The two thermom eters were carefully compared. They were placed, after filling the hollow bulb of one with the emanation obtained in five days from 162 milligrammes of radium bromide, in two silvered vacuum vessels, and they rested in cotton-wool, with which the vacuum vessels were lightly packed. These vessels were placed side by side in a room of which the temperature remained nearly constant. The following table gives the differences between the two temperatures; needless to say, that of the thermometer containing the emanation was the higher:

$\begin{array}{lrrrrrrrrrrr}\text { Date-November. } & 20 . & 21 . & 22 . & 23 . & 24 & 25 . & 26 & 27 . & 28 . & 29 . & 30 . \\ \text { Difference, deg... } & 0.52 & 0.73 & 0.63 & 0.53 & 0.48 & 0.34 & 0.25 & 0.23 & 0.19 & 0.16 & 0.13\end{array}$

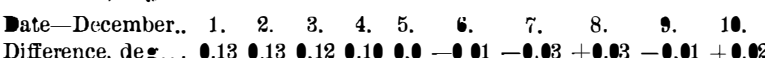

These figures show incontestably that the emanation evolves heat during its change, and that the amount liberated decreases from day to day.

2. The Relative Amounts of Oxygen and Hydrogen Evolved, along with Emanation, by the Action of Radium Bromide on Water.-Giesel (Ber., 1902, 35, 360 ; also $1903,36,347$ ) was the first to observe this decomposition; Bodländer found the gaseous mixture to contain 12 per cent of oxygen and 88 per cent of hydrogen; the excess of hydrogen was 64 per cent Later, Ramsay and Soddy (loc. cit.) found 29.8 per cent of oxygen and 70.2 per cent of hydrogen; the excess of hydrogen is 10.6 per cent. Whence comes this excess? They ascribe it to the oxidation of the grease of the stop-cock; but that danger was avoided in the work of which an account will be given. The following experiments were made in the hope of solv ing this problem.

The first question to be answered was: Does radium bromide evolve gas when dissolved? A very pure sample of bromide, bought from Büchner \& Co., of Brunswick, was employed. It is worth noting that five samples of bromide, bought from that firm at different times, all had the same relative discharging power on an electroscope, as measured by the $\beta$-rays evolved, and the natural conclusion is that they all possessed the same degree of purity. The volume of the gas obtained from the sample used (which weighed 50 milligrammes), on dissolving it in water, was 0.1444 cubic centimeter; after explosion the volume was 0.0477 cubic centimeter; the residue consisted solely of hydrogen, mixed with a trace of helium, the latter detected by its spectrum. Now, crystalline bromide probably contains two molecules of water, which should be resolved into oxygen and hydrogen by the action of the radium. The excess of hydrogen is 33 per cent, and it must be supposed that the gases were
occluded by the bromide and liberated on its being dissolved.

The next experiments, made at considerable intervals of time, show the yield of "electrolytic gas," with the excess of hydrogen, obtained from varying amounts of radium bromide:

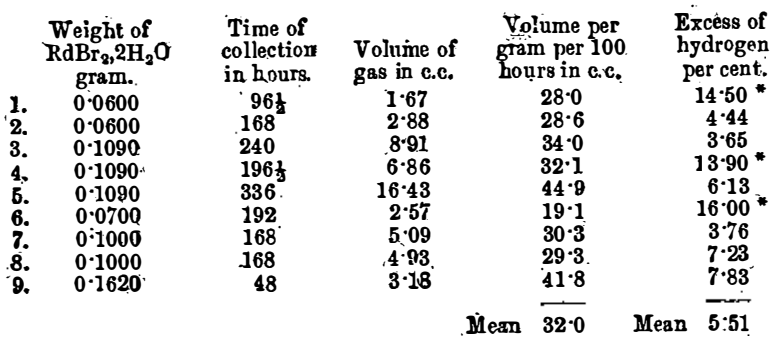

The inequality in these results may be accounted for by several considerations. First, the emanation is soluble in water, and it decomposes water; hence, if the gases remain in contact with the solution, more the pump shortly after their liberation. Second, the emanation causes recombination of hydrogen and oxygen at a rate which depends on the amount present and probably on the temperature. Third, the emanation causes oxygen to attack mercury when they are left in contact. The following special experiment llustrates this fact.

The initial volume of a mixture of emanation with pure oxygen was 2.13 cubic centimeters; after being kept for five days over mercury it had decreased to * The quantities markel with an asterisk had remained in contact with mercury for a night before being measured. They have been omitted in
taking the mean.
1.97 cubic centimeter, and the surface of the mercury had become coated with a white deposit, which gradually changed to red, and appeared to consist of meruric oxide. A similar experiment with hydrogen left the surface of the mercury undimmed.

For these experiments on the volume of "electrolytic" gas produced by the emanation, the radium bromide was dissolved in water in little bulbs, sealed to a common tube connected with a Töpler pump. To prevent possible leakage, after each removal of gas the reservoir of the pump was raised so as to cause the mercury to leak past the valve and to pass a stopcock closing the tube connected with the bulbs; the gases were thus confined by mercury and did not come into contact with the grease of the stop-cock. The entrance tube to the pump was capillary, and so the surface of contact of gas and mercury was very small; the excess of hydrogen cannot be abscribed to the attack of the mercury. Even in experiments 1, 4, and 6 , when the gases remained for a night in contact with a large surface of mercury in the collecting tube, of 1.5 centimeter diameter, the mercury was not much attacked. The arrangement prevented the attack of the grease by the oxygen in presence of emanation; before it was adopted, carbon dioxide was always detected spectroscopically, but after its adoption none was present.

To account for the excess of hydrogen, several hypotheses may be suggested. It is conceivable that hydrogen may be one of the products of disintegration of radium; but it is very improbable that it should be formed in such large amount. An experiment may be cited here which bears on the subject. A bulb containing 17 milligrammes of radium bromide was sealed to the pump. The color of the bromide was chocolate-brown, but some hours after a vacuum had been made its color changed to white, and it appeared to have dried. After standing for a day. a little gas waś pumped off; it did not explode on passing a spark, but after it had been mixed with half ts volume of oxygen, a spark caused explosion, and there was no visible residue. Some days later, a second bubble was extracted: when introduced into a vacuum tube, it showed the spectrum of hydrogen; week later no gas could be pumped off.

It is well known that minerals containing thorium and uranium always contain helium (Ramsay and Travers, Proc. Roy. Soc., 1897, 62, 328); and some months after the discovery of helium an attempt was made to ascertain whether the helium existed in a state of combination with one of the constituents of the mineral Several experiments were made in which the mineral was heated with hydrochloric or sulphurlc acid, and the ratio of the hydrogen to the helium in the liberated gas was determined. The problem, however, was complicated by the fact that ores of uranium always contain that element as $\mathrm{UO}_{3}$, which is reducible by hydrogen to $\mathrm{UO}_{2}$; it would otherwise be possible to deduce the valency of helium. An imaginary example will make this conception clear. Suppose that ammonia were so unstable that immediately on its liberation it were to decompose into hydrogen and nitrogen. If it were required to determine the valency of nitrogen in magnesium nitride, the action of water, which actually liberates ammonia, would, under the supposed conditions, yield a mixture of one volume of nitrogen with three of hydrogen. The absorption of the hydrogen by a reducible agent would prevent the accuracy of such an experiment.

Our knowledge of the transformation of radium emanation into helium alters the problem. It is no longer likely that helium is contained in the mineral in a state of combination; it is almost certain that the gas is distributed through the mineral in a molecuar condition, having been formed in situ owing to the disintegration of the radium in the uraninite; or possibly owing to the disintegration of the uranium itself, though we do not know whether helium is one of the products of the disintegration of uranium. Still, it must be noted that if a-rays consist of helium, they are emitted during the change of uranium into uranium $\mathrm{X}$

Returning to the question, Is hydrogen one of the products of the disintegration of the emanations of radium and thorium? some help may be gained by considering thorianite, the cubical mineral from Ceylon. It contains little reducible oxide, and when heated or dissolved it yields a relatively large amount of helium. It has been found, and will be described in subsequent paper, that thorium nitrate from thorianite probably yields helium on standing, and $\mathrm{De}$ - 
bierne has shown that helium is also one of the products of disintegration of actinium. Now thorianite, heated in the vacuum with sulphuric acid diluted with its own volume of water, gives very little, if any, hydrogen. From 1.3779 grammes of the mineral, I obtained 8.37 cubic centimeters of gas, after removal of carbon dioxide; oxygen was added, and sparks were passed for half an hour; after removal of the oxygen with phosphorus, the residue, measuring 8.05 cubic centimeters, consisted of pure helium; the volume of the hydrogen was therefore 0.32 cubic centimeter, or 0.23 cubic centimeter per gramme; the atomic proportion would be one atom of hydrogen to thirteen of helium.

In a second experiment, where the thorianite was fused with sodium hydrogen sulphate, a mixture of sulphur dioxide, oxygen, and helium was obtained. Part of the sulphur dioxide owes its origin to the decomposition of sulphuric anhydride; by estimating the oxygen, calculating it to sulphur dioxide, and subtracting that quantity from the total sulphur dioxide, the remainder, 16.34 cubic centimeters, was evidently produced by the oxidizing action of sulphuric acid on the $\mathrm{U}_{3} \mathrm{O}_{8}$, which was transformed into $3 \mathrm{UO}_{3}$, and on the $2 \mathrm{FeO}$, converted into $\mathrm{Fe}_{2} \mathrm{O}_{3}$; this would have required 16.30 cubic centimeters of sulphuric dioxide. It may be stated, therefore, that hydrogen is probably not one of the products of the disintegration of thorium, and, from analogy, a similar conclusion may be drawn as regards radium bromide.

The hydrogen pumped off from the solid radium bromide is in all probability derived from the water of crystallization of the salt. But the question still remains unanswered-whence arises the excess of hydrogen? What becomes of the oxygen?

A second possibility is that the radium bromide is decomposed into metallic radium (which would attack the water and yield hydrogen) and into bromine (this suggestion has been made, indeed, by Giesel); and bromine is easy to identify. Or, again, it may be suggested that ozone is a product of the action of radium on water, and consequently the initial volume would be too small. But ozone, like oxygen, explodes quantitatively with hydrogen, so that its presence would not account for the excess of hydrogen.

To test these suppositions, the following experiment was made. A bulb containing 70 milligrammes of radium bromide, dissolved in water, was sealed to a small U-tube containing a faintly acid solution of otassium iodide and starch. During seven days, bubbles of gas passed through this solution, but no blue color was seen, even on heating the bulb, so as to expel any trace of bromine which might have been liberated. This would also exclude ozone. It has been remarked that the odor of ozone may be perceived on opening a capsule containing radium bromide; I have opened many capsules, and I have never noticed this. Moreover, an experiment which has been in progress for more than two years negatives the supposition. The gases from 212 milligrammes of radium bromide have been removed every two or three days by means of a Töpler pump. The mercury shows no trace of ozonide; it is absolutely untarnished, and has shown no tendency to wet the walls of the pump. A single bubble of ozonized oxygen would, as is well known, cause the mercury to adhere to the glass, and render the pump useless until cleaned. It may therefore be taken as certain that ozone is not produced by the action of radium bromide on water, in absence of organic matter. I have no experiments to show whether the presence of organic matter might not lead to its formation.

Yet another two suggestions may be made. They are that the radium bromide may be oxidized to bromate, or that hydrogen dioxide may be formed. To test this, I added a drop of a mixture of iodide of potassium and starch, slightly acidified, to an old solution of radium bromide; no coloration was visible. These hypotheses must also be rejected.

3. The Action of Radium Emanation on WaterAs already mentioned, the amount of energy evolved during the spontaneous transformation of radium emanation is enormous. Supposing the density of the emanation to be 108,1 milligramme liberates no less than 720,000 gramme-calories in thirty days. Supposing, too, that all this energy were expended in decomposing water, it should be sufficient to resolve nearly 200 grammes of water into oxygen and hydrogen.

Looking at the question somewhat differently, one cubic millimeter of emanation should liberate about 2.3 liters of explosive gas, if all energy were to be expended in that manner. But although the emanation does decompose water, the amount of water decomposed is far from the quantity mentioned.

The experiments were carried out in the following manner. The bulb $A$ (Fig. 1) contained three or four cubic centimeters of pure distilled water. The inverted siphon, $B$, dipping under mercury in the reservoir, was sealed at $C$ in such a way that the least pressure broke off its capillary point. The water was then frozen with liquid air, and a vacuum was made through $D$, which was sealed to a Töpler punp. The stop-cocks were then closed, and the emanation drawn from the dissolved radium bromide, and mixed with oxygen and hydrogen, contained in the small gas-tube, $E$, was introduced after explosion into the bulb by pressing the tube down on the point $C$. The gas entered the capillary tube up to the closed stop-cock, $F$ This stop-cock was then cautiously opened, and al gas entered the cooled bulb, care being taken not to introduce any mercury. After some minutes, al emanation had condensed, and the stop-cock, $g$, was opened, and the excess gas, consisting chiefly of hydrogen, was pumped off. Operating in this manner, th bulb contained only water and emanation. The gas removed before sealing the capillaries at $H$ was ana yzed.

To insure complete contact between water and emanation, the bulb was attached to the crank of a small hot-air engine, and shaken continuously for a month. The results of three experiments are given in the following table:

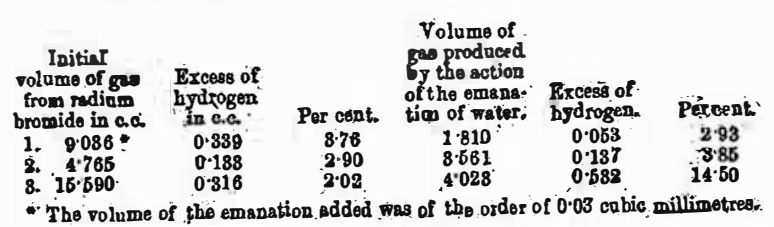

I cannot explain the third result; there was no oxidizable matter in the bulb, and the experiment was well carried out.

It is evident that the emanation alone can decom pose water, and that it yields excess of hydrogen. The cause of this excess cannot be any one of the possible ones already considered, except the formation of hydrogen peroxide, but even that is excluded by this experiment: the bulb containing the water after gas had been pumped off, was left in connection with a tube filled with phosphoric anhydride until all the water had evaporated and had been absorbed by

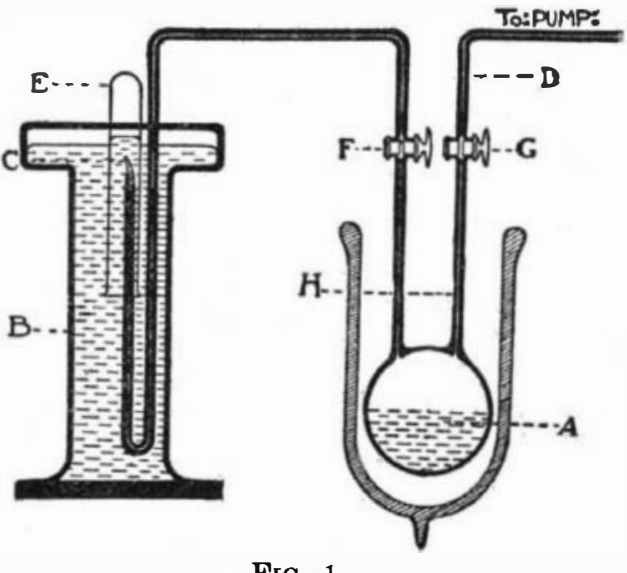

FIG. 1.

the anhydride. A minute bubble of gas was collected; on explosion, it gave absolutely no residue. Had the water contained peroxide, this bubble should have consisted of oxygen. In the other two experiments the water was tested by means of iodide of potassium and tarch; there was no liberation of iodine.*

4. The Action of the Radium Emanation on a Mixture of Oxygen and Hydrogen.-An experiment was next made to ascertain whether the presence of the emanation would cause combination of oxygen and hydrogen; the gas extracted from the radium bromide was suitable for this purpose. . Some of this mixture

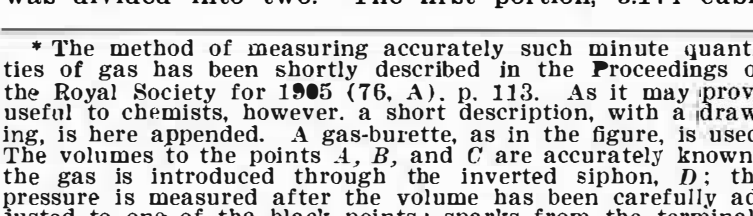

the gas is introduced through the inverted siphon, Di the
pressure is measured after the volume has been carefully add-
justed to one of the black points; sparks from the terminals

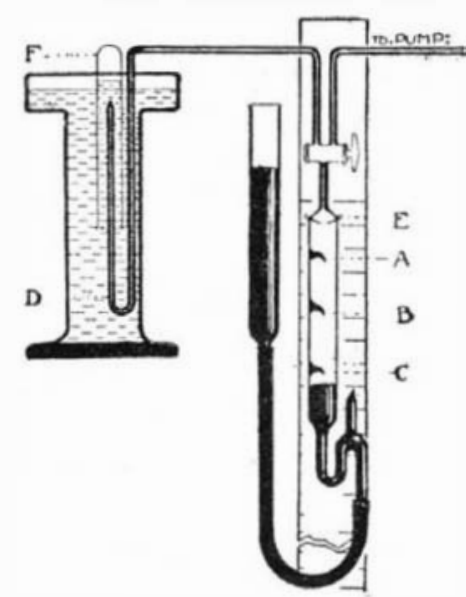

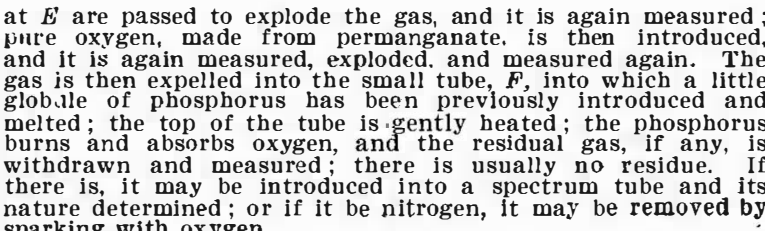

centimeters, was exploded; it gave 0.179 cubic cen timeter of hydrogen in excess, or 5.64 per cent. The second portion was sealed into a bulb on January 29, 1905; it was opened on February 20. It consisted originally of 2.120 cubic centimeters, and its final volume was 1.483 cubic centimeter, equivalent to a recombination of 30 per cent of the original gas. On explosion, a residue of hydrogen was obtained, equal to 5 per cent of the original volume, 2.120 cubic centimeters.

A second experiment, in which 2.035 cubic centimeters of mixed gases were sealed up with the emanation on November 20,1906, the bulb was opened on December 27, and its volume was then 1.480 cubic centimeters, equivalent to a recombination of 27.2 per cent of the original gas; it contained 5.61 per cent of excess hydrogen, reckoned on the volume 2.035 .

It appears, then, that oxygen and hydrogen recombine in presence of the emanation. The gases were dry when introduced into the bulb, and they were at a reduced pressure, probably about a quarter of an atmosphere, while exposed to the emanation. It may here be mentioned that Messrs. Berger Davis and C. W. Edwards (J. Soc. Chem. Ind., 1905, 24, 266) noticed that solid radium bromide, left in contact with a mixture of oxygen and hydrogen, induces slow ombination.

These experiments prove that the action of the emanation on a mixture of oxygen and hydrogen is a reversible reaction, and that the velocity of decomposi-
tion of water is greater than that of recombination of the resulting gases, for water is decomposed by emanation.

5. The Rate at which Water Is Decomposed by Emanation. - It is difficult to solve this problem, on account of disturbing factors. These are: (1) At the beginning of the experiments the emanation is wholly dissolved in the water. After some hours, gas is evolved, and the emanation divides itself between the water and the gaseous mixture, in such a manner that that part of the emanation which remains in solution decomposes the water, and it is to be presumed that the portion mixed with the gases causes them to recombine. An experiment has not been made (and it would be very difficult to carry out) to test whether steam is decomposed by the emanation. (2) It was impossible to prevent the gaseous mixture touching the stop-cock, and consequently coming into contact with grease; when this occurs, carbon monoxide and dioxide are produced. (3) It was impracticable to avoid the use of mercury, and it has been mentioned that mercury is oxidized. But below the fairly deep layer of water the mercury, it should be noted, remained untarnished. Hence the results do not show correspondence between the amount of emanation present and the quantitative action on water. Moreover, it is not improbable that some of the products of the change of the emanation have also an action in decomposing water, although nothing is known as regards this. In spite of these objections, the results are perhaps worth recording.

The initial gas was obtained from 212 milligrammes of radium bromide in three days; its volume at normal temperature and pressure was 3.935 cubic centimeters. After explosion, the excess of hydrogen was removed by addition of a sufficient quantity of oxygen; the final residue, amounting to 0.093 cubic centimeter, was introduced over several cubic centimeters of water, standing over mercury in a measuring-tube provided with a black point, to which the level of the water could be adjusted. The minute bubble was well shaken with the water, and allowed to stand from November 25 , 1905, until January 8, 1906; and daily readings were taken, temperature and pressure being noted and the pressure of water-vapor allowed for. The readings are as follows:

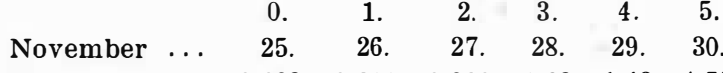

$\begin{array}{lllllll}\text { C. c } \ldots \ldots \ldots & 0.093 & 0.611 & 0.980 & 1.23 & 1.42 & 1.57\end{array}$

$\begin{array}{cccccccc}\text { December ... } & 1 . & 2 . & 3 . & 4 . & 5 . & 6 . & 8 .\end{array}$

$\begin{array}{llllllll}\text { C. c. } \ldots \ldots & 1.66 & 1.74 & 1.79 & 1.84 & 1.88 & 1.94: & 1.98\end{array}$

$\begin{array}{cccccccr} & 13 . & 14 . & 15 . & 16 . & 17 . & 18 . \\ \text { December ..... } & 9 . & 10 . & 11 . & 12 . & 13 . & \text { Jan. } 8 .\end{array}$

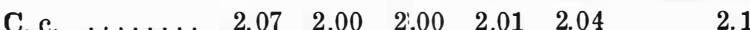

This final gas was then analyzed.

Assuming that the initial gas present was oxygen, it composition was:

Oxygen originally present... 0.093 c. c.

Carbon dioxide

Hydrogen and oxygen......... 0.726

Excess hydrogen .......... 0.471 "' equivalent to

2.140 c. c. 23.0 per cent

It would be natural to suppose that if all emanaion remained dissolved, not escaping into the gases produced, the rate of decomposition of the water would be proportional to the rate of decay of the emanation, supposing the decomposition of the emanation to be due solely to the latter; if, however, the decay of 
other products, radium $\mathrm{A}$, radium $\mathrm{B}$, and radium $\mathrm{C}$, is also accompanied by the decomposition of water, the problem becomes a very complicated one.

The curve obtained by plotting the rate of increase or the gases formed against time shows a much mor rapid increase than the rate of decay of the emanation would warrant. The period of half-value of the emanation is 3.8 days, that of the increase of gases is 2.53 days. The curves, however, resemble each other in character. The lives of radium $A$, radium $B$, and radium $C$, are very short, their combined halfperiod of decay being less than an hour; but as they are being continuously produced, owing to the decay of the emanation, a constant maximum is quickly produced, which falls off as the emanation decays. Attempts to allow for this disturbing influence have been made, but without success, and it appears probable that the partition of the emanation between gas and water, and the recombination of the hydrogen and oxygen in the gaseous system, render any such attempts futile in the present state of our knowledge.

\title{
DESTRUCTIVE MARINE WOOD BORERS.
}

\section{VARIOUS METHODS OF PROTECTING TIMBER STRUCTURES.}

\author{
B Y C H A R L E S. M. R I P L E Y, M.E.
}

ON both the Pacific and the Atlantic coasts, reports from railroad and other engineers indicate that the action of the terelo during the past summer has caused great destruction through docks, trestles, bridges and other structures over salt walter: The farthest point north which the teredo has yet attained according to reports has been Nova Scotia on the At lantic coast and Alaska on the Pacific coast. Civi engineers are devoting serious thought to the matter and particularly in the vicinity of New York this subject has demanded attention of late.

At an early stage of grow th the teredo is free swimming, traveling about in the water and attacking any woôdwork which may have been left exposed, entering it by a hole not larger than a pin head. After they have started their boring the teredoes grow not only in length but also in diameter, and sometimes have been known to have reached diameters as great as three-fourths of an inch. The teredo is whit ish in color, and has two small flexible tubes or siphons continuously extending into the water from the small entrance hole in the wood. It is very important that these vital organs be constantly submerged in comparatively pure salt water, as it is through these organs and from the water that the through these organs and from the water that the substance which will permanently cut off the surface of the wood from contact with pure salt water, will not only kill the teredoes that are already in a pile but will prevent the entrance of other teredoes.

It is extremely difficult to inspect a pile and discover the presence of the teredo until a vast amount of damage has been done, for the reason that although the interior may be perfectly honeycombed, the exterior presents an almost perfect appearance. The writer took occasion to weigh a 3 -foot section of a 12-inch pile which had been withdrawn from a bridge in a bay within a radius of 50 miles of New York city, and was astonished to find that the weight of the section mentioned was but 11 per cent of its original weight as yellow pine, which was calculated on a basis of 0.9 specific gravity. This fact was more astonishing since there were no openings upon the exterior of the pile save the tiny holes at which the teredo originally entered.

Railway engineers have planned and worked for years to prevent the action of teredo, limnoria, and other marine wood borers which destroy the piles of

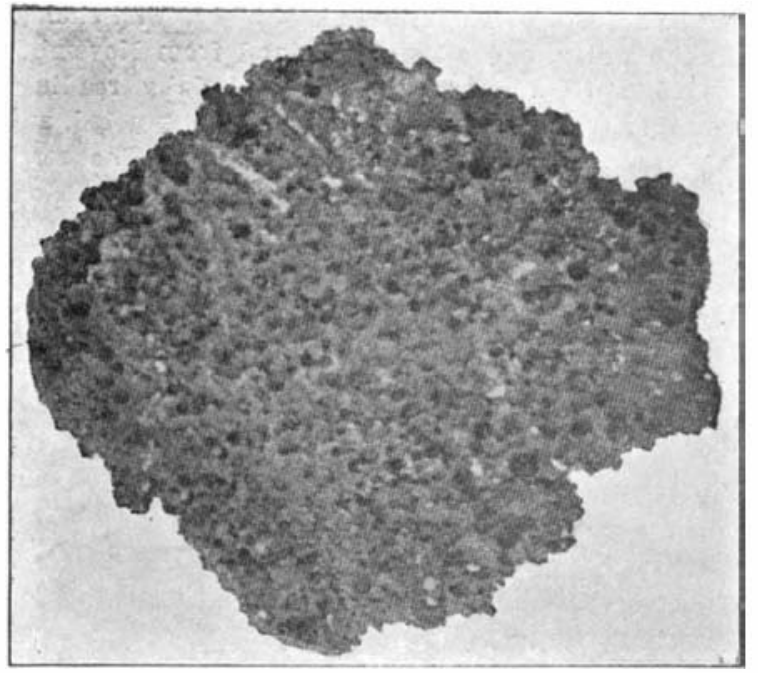

A SECTION OF A BALK RIDDLED BY TEREDOES

docks, wharves, bridges, and trestles in the regions where salt water is to be spanned.

It was once attempted in Holland to preserve the piling of dikes by means of driving thousands of roundheaded iron tacks into the pile. Small boys were employed for this purpose and more or less success attended it, but the expense is obviously prohibitory and on existing structures the work can only extend from low water upward unless the services of a diver were employed.

The copper sheathing method is a good protection. However, copper is liable to corrode in salt water not only at the joints, but around the nail heads. The expense, both for material and for labor, in applying copper is to be considered, as is also the fact that the exact depth to which a pile is to be driven is not

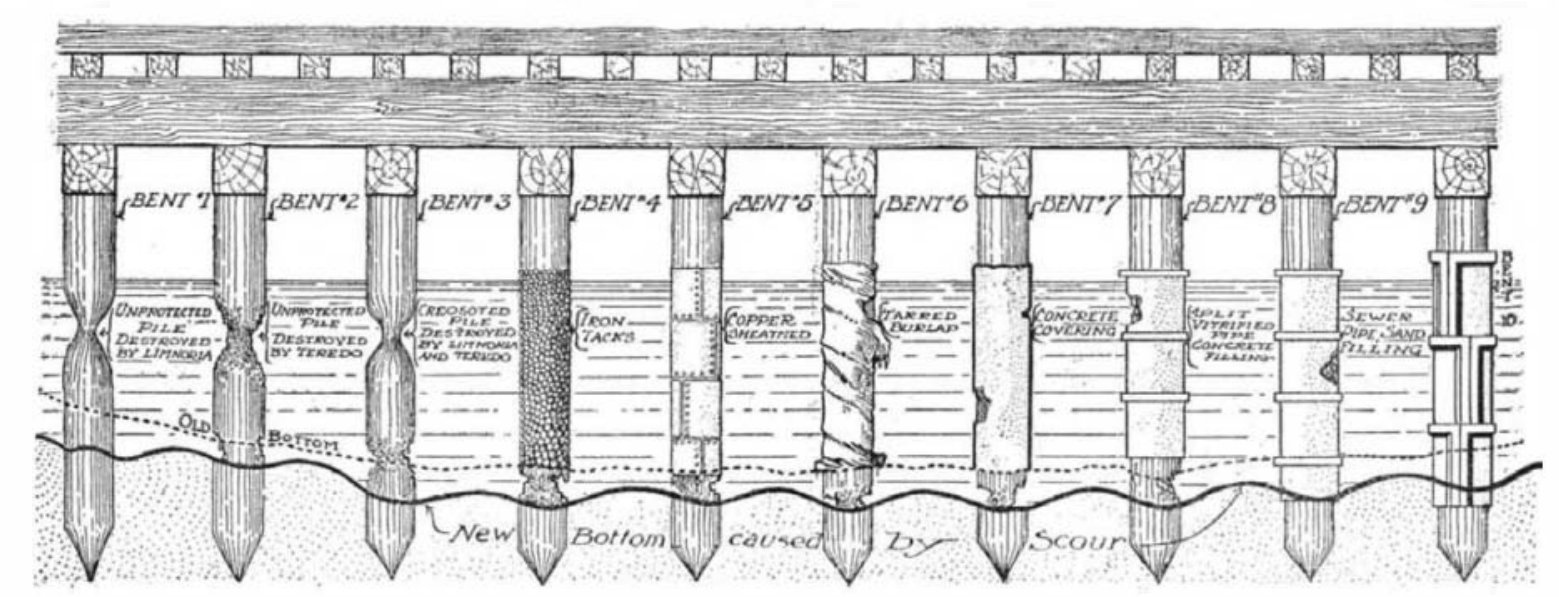

THE VARIOUS ME'THODS OF PROTECTING WOOD PILES FROM SALT WATER WOOD-BORING MOLLUSKS.

$$
\begin{aligned}
& \text { which of ten la ys piles bare } \\
& \text { confrontung the engineer. }
\end{aligned}
$$

always known in advance, and hence the cupper sheathing is likely to be made to extend either too close to the bottom of the pile, where it is useles in the mud, or too high toward the top of the pile where it is unnecessary above the high water line. Later engineers have attempted to protect piles by means of tarred burlap wound spirally around the pile. Materials floating down stream tended to tear the burlap; also barnacles and oysters clinging to the material after the tar was more or less covered with weeds and slime tended to pull away the protection and leave the pile exposed near the top.

The lowering of the old mud line often occurs where the stream is narrowed by the introduction of piling or other obstructions. The tar burlap neces sarily has difficulty penetrating the old mud line as the pile is driven, and hence as the mud line late recedes, the pile is left exposed at the bottom, a point which cannot be inspected without a diver.

Concrete has been used as a coating around piles, molds being placed by divers and the concrete poured in; one difficulty incidental to this method has been that as the mixture was poured down through the water in the mold it tended to weaken. Cases have been found where piles protected by this method were really exposed at the bottom, since nothing but gravel descended through the water to that depth and the teredo could enter the interstices between the grouting.

A later attempt is split vitrified pipes placed around the pile, held in place by wires, and then filled with concrete.

Another method is ordinary sewer pipe strung over the top of the pile and filled with sand. This method overcomes the difficulty mentioned in connection with a concrete covering or filling, as the sand filling allows the sewer pipe to descend as the mud lin recedes, but in a new structure this method must be installed before the deck is placed. In old structures caps of the piles must be removed before the pipes can be placed. This obviously interferes with the speed of construction of new work and also interferes with traffic when applied to old structures. A serious objection is that repairs to one section or one pile necessitate the removal of the cap from that entire bent.

Many of the various sheathings used may develop a weakness in course of time; and if one vulnerable spot shows, the teredo may enter in and work destruction through the pile. All the methods mentionedwith the exception of the sewer pipe-are liable to undermining. The coverings are attached to the pile, and if the scour of the water removes the wood or earth from the base, a line of attack is offered to the teredoes.

An improvement on the sewer pipe is the new lockjoint pipe. This consists of sections of a concrete pipe, cast in halves so that it may be bolted round pile when the latter is in position. The pipe is larger than the pile, and the space between is filled
up with fine sand. Thus it is claimed that the pipe up with fine sand. Thus it is claimed that the pipe follows the mud line, always keeping the pile protected throughout the field of attacks of the marine wod throughout the field of attacks of the marine ion to know that th continued access to the water in order to live. It is thus impossible for the teredo to enter a pile above this protection and live so long as this protection stands above the high water mark.

This system can be applied to old structures as easily as to new, without removing the deck, without interfering with traffic and without the necessity of employing a diver and his expensive outfit. Inspection is a simple matter since sand showing at the

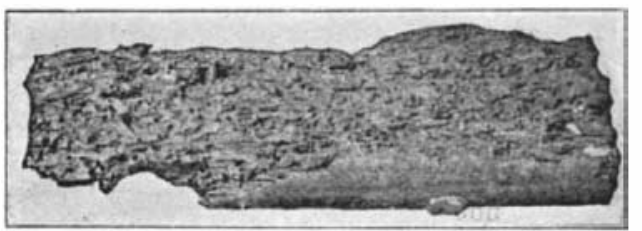

ANOTHER EXAMPLE OF TEREDO DESTRUCTION.

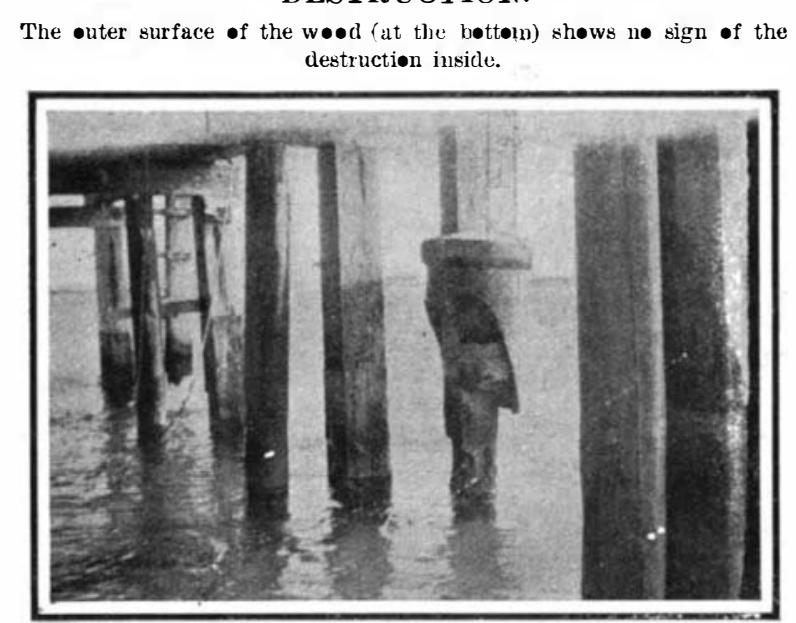

WHERE THE TEREDO DOES HIS WORK.

top assures sand in place down to the lowest mud line.

Green spot soap consists of 400 parts each of cocoa nut oil, kidney suet, and 40 per cent lye, 50 parts of ox-gall and 25 parts each of oil of turpentine and ultramarine blue. 